\title{
The epidemiology of osteoporosis in Italian postmenopausal women according to the National Bone Health Alliance (NBHA) diagnostic criteria: a multicenter cohort study
}

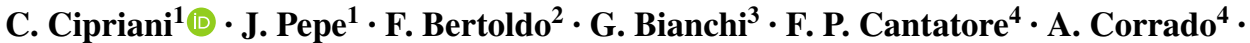

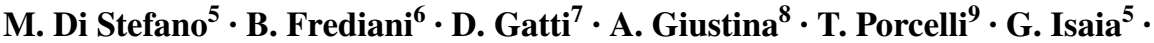 \\ M. Rossini ${ }^{7} \cdot$ L. Nieddu ${ }^{10} \cdot$ S. Minisola ${ }^{1} \cdot$ G. Girasole ${ }^{3} \cdot$ M. Pedrazzoni ${ }^{11}$
}

Received: 1 August 2017 / Accepted: 8 September 2017

(C) Italian Society of Endocrinology (SIE) 2017

\begin{abstract}
Purpose The study was aimed at evaluating the prevalence of osteoporosis, defined by BMD and the National Bone Health Alliance (NBHA) criteria, and the prevalence of clinical risk factors for fractures in Italian postmenopausal women.

Methods This is a cross-sectional, multicenter, cohort study evaluating 3247 postmenopausal women aged $\geq 50$ and older in different areas of Italy in the period 2012-2014. All the participants were evaluated as far as anthropometrics; questionnaires for FRAX ${ }^{\circledR}$ and DeFRA calculation were administered and bone mineral density was measured at lumbar spine, femoral neck and total hip by DXA.

Results The prevalence of osteoporosis, as assessed by BMD and NBHA criteria was 36.6 and 57\%, respectively. Mean \pm SD values of FRAX ${ }^{\circledR}$ and DeFRA were: $10.2 \pm 7.3$ and $11 \pm 9.4$ for major fractures, and $3.3 \pm 4.9$ and $3.9 \pm 5.9$ for hip fractures, respectively. Among clinical risk factors for fracture, the presence of previous fracture, particularly
\end{abstract}

C. Cipriani

cristiana.cipriani@gmail.com

1 Department of Internal Medicine and Medical Disciplines, "Sapienza" University of Rome, Viale del Policlinico 155, 00161 Rome, Italy

2 Internal Medicine, Department of Medicine, University of Verona, p.le L. Scuro 2, 37134 Verona, Italy

3 Division of Rheumatology, Department of Locomotor System, ASL3-Azienda Sanitaria Genovese, Genoa, Italy

4 Rheumatologic Clinic “M. Carrozzo", Department of Medical and Surgical Sciences, University of Foggia, Foggia, Italy

5 Gerontology and Bone Metabolic Disease Section, Molinette Hospital, University of Turin, 10126 Turin, Italy non-spine/non-hip fracture, parental history of hip fracture and current smoking were the most commonly observed. Conclusions Our study showed that more that the half of postmenopausal women aged 50 and older in Italy has osteoporosis on the basis of the NBHA criteria. There is a relevant high risk of femur fracture, as assessed by the FRAX ${ }^{\circledR}$ and DeFRA and previous fracture, parental history of hip fracture and current smoking are the most common risk factors. The data should be considered particularly in relation to the need to increase prevention strategies on modifiable risk factors and therapeutic intervention.

Keywords Osteoporosis · Fracture · Risk factors · Italy · FRAX $^{\circledR} \cdot$ DeFRA

6 Department of Rheumatology, Policlinico Le Scotte, University of Siena, Siena, Italy

7 Rheumatology Section, Department of Medicine, University of Verona, Piazzale L. Scuro 10, 37134 Verona, Italy

8 Vita-Salute University San Raffaele Milan, Milan, Italy

9 Presidio Ospedaliero di Montichiari, Via G. Ciotti, 154, 25018 Montichiari, Brescia, Italy

10 Faculty of Economics, UNINT University, Via Cristoforo Colombo 200, 00147 Rome, Italy

11 Department of Clinical and Experimental Medicine, University of Parma, Via Gramsci 14, 43126 Parma, Italy 


\section{Introduction}

Osteoporosis is defined on the basis of reduced bone mineral density (BMD) and altered skeletal microarchitecture, with consequent increased risk for fracture. The use of dualenergy X-ray absorptiometry (DXA) to measure BMD is the universally accepted method to diagnose osteoporosis, but recent recommendations pointed out that the diagnostic criteria should also include the presence of low trauma fractures and/or an elevated fracture risk [1-6]. In particular, the National Bone Health Alliance (NBHA) Working Group recommended that postmenopausal women and men over 50 should be diagnosed to have osteoporosis based on DXA $\mathrm{T}$-score $\leq-2.5$ and on the presence of low-trauma hip fracture (independently of BMD) or in presence of osteopenia by BMD and low-trauma vertebral, proximal humerus, pelvis, or distal forearm fracture in some cases [5].

The identification of risk factors contributing to bone fragility and fractures has led in the last decade to the definition of models and algorithms for the assessment of 10-year individuals' risk of fracture [7]. Among BMD-independent factors, clinical risk factors are of utmost importance in the identification of patients at high risk and are routinely employed in clinical practice, particularly in the FRAX ${ }^{\circledR}$ calculation [7]. The presence of an elevated fracture risk as assessed by FRAX ${ }^{\circledR}$ has been included in the definition of osteoporosis (10 year hip fracture risk of $\geq 3 \%$ or major osteoporotic fracture risk of $\geq 20 \%$ ) [5]. The derived FRAX $^{\circledR}$ algorithm, DeFRA was developed by the Italian Society for Osteoporosis, Mineral Metabolism, and Skeletal Diseases (SIOMMMS) with the aim of further increase the sensitivity of fracture risk assessment and its validation is still ongoing $[8,9]$. It can be used only in postmenopausal women aged 50-90 and includes a deeper and more accurate analysis of the "classical" clinical risk factors included in the FRAX $^{\circledR}$ related to previous fractures, cigarette smoking, alcohol, corticosteroid use and rheumatic diseases, as well as the inclusion of either lumbar spine or neck BMD [8]. The rationale of DeFRA derived from epidemiological and cohort studies showing a strong association between the quantification of risk factors and fractures [10-15].

Epidemiological studies showed different data on the prevalence of osteoporosis and fragility fractures [16-18]. The disparity can be explained based on differences among populations from various geographical areas, differences in the socioeconomic status and in the ethnicity. Additionally, secular trends in the incidence of osteoporotic fracture has been observed over several decades [16-18]. Recent data from US reported that $10.3 \%$ of adults (10.2 million) 50 years and older in the NHANES population (2005-2010) have osteoporosis when the diagnosis is made using lumbar spine and femoral neck BMD, with a $43.9 \%$ prevalence of low bone mass [19]. The application of the NBHA criteria to the NHANES 2005-2008 data showed a 16\% prevalence of osteoporosis in men and $29.9 \%$ in women aged 50 and older [20]. Data on the prevalence of osteoporosis in the Italian population are limited and rely mainly on the evaluation of osteoporosis in selected populations [21, 22]. The only cross-sectional study performed in the general population applied the quantitative heel ultrasound technology to assess the prevalence of osteoporosis, reporting a $18.5 \%$ rate of osteoporosis and $44.7 \%$ of osteopenia in women aged 40-79 [23]. However, as far as risk factors, Bonaccorsi et al. [22] found the highest prevalence of smoking (12.9), parental history of hip fracture (11.2\%) and secondary osteoporosis (10.3\%) among women aged 50-90 referring to a single tertiary care center. No study so far has dealt with the issue of prevalence of osteoporosis, as evaluated by BMD and NBHA criteria, nor has assessed the prevalence of clinical risk factors for fractures in the Italian population. We report data from a cross-sectional, multicenter, cohort study primarily aimed at addressing these issues, together with the evaluation of both FRAX ${ }^{\circledR}$ and DeFRA algorithms and their sensitivity in predicting fracture risk.

\section{Methods}

We studied 3247 postmenopausal women aged 50 and older in different areas of Italy in the period 2012-2014. Eight referring Centers for the study of Metabolic Bone Disease were involved in 7 different cities allocated in the north, center and south of the country: Brescia (53 women), Foggia (73), Genoa (1016), Rome (441), Siena (173), Turin (69), Verona (471 and 951). The general practitioners connected to the osteoporosis center directly contacted all the postmenopausal women aged $\geq 50$ referred to their primary care clinic and referred them to the center. The original number of women contacted was 4330; the response rate was, therefore, of $75 \%$. Clinical characteristics of women who refused to participate the study were not different from those who participated. All the participants were evaluated as far as anthropometrics; body weight was measured to the nearest $0.01 \mathrm{~kg}$ using an electronic load cell scale, and standing height was measured with a fixed stadiometer. BMI was calculated as body weight (kilograms) divided by height (meters squared). Subjects were administered the questionnaires for FRAX ${ }^{\circledR}$ and DeFRA calculation and including: demographic data, previous fracture (yes/no; spine, femur-specifying if 1,2 or more; non-spine non-femur after 50 years of age-specifying if 1,2 or more), parental history of femur fracture, smoking (yes/no; $<10$ or $\geq 10$ cigarettes/day), corticosteroids use (yes/no; $>2.5<5 \mathrm{mg} /$ day or $>5 \mathrm{mg} /$ day), rheumatoid arthritis, alcohol (yes/no) and secondary causes of osteoporosis. 
Bone mineral density was measured at the lumbar spine (L1-L4), femoral neck (FN), and total hip (TH) by DXA (QDR-4500; Hologic Inc. and Lunar Prodigy, GE Healthcare) in any center. The DXA machines were cross-calibrated at the beginning of the study using the same spine phantom scanned ten times in any center. All the centers performed machine calibration daily. Lumbar vertebrae were excluded from BMD measurement if degenerative diseases, fusions, or fractures were recorded at the study visit or noted in the image. The hip was not scanned when a positive history of fracture or surgery was present. Both lumbar vertebrae and/or the femur were excluded from the scan when any of the following was present: removable or non-removable objects (e.g., implants, prosthesis), excessive X-ray "noise" due to obesity, positioning issues, self-report of an imaging procedure using contrast material in the previous 7 days, participant movement during the scan, and, in the case of femur scans, panniculus. Lumbar spine and femur BMD data were converted to the Hologic based data using the standardization approach described by Genant et al. [24] to provide compatibility of DXA results obtained on different scanners. BMD values of healthy premenopausal women aged 20-45 and of healthy men aged 20-40 were defined as the peak bone mass and used for the calculation of T-score at the lumbar spine [25]. The reference group for T-score calculation for femoral neck consisted of 20-29 aged nonHispanic white subjects of both sexes from NHANES III, as recommended by the WHO [26, 27]. These reference values were used because the BMD values observed in the first 3 decades in healthy Italian women and men are virtually identical to those of the NHANES study [25]. All DXA scans were centrally read by the same radiologist (DD).

The assessment of the individual 10-year fracture risk for major fractures and hip fractures was done using the clinical risk factors and femoral neck BMD and T-score. The FRAX ${ }^{\circledR}$ tool for Italy (http://www.shef.ac.uk/FRAX) and DeFRA (https://defra-osteoporosi.it) were used.

Osteoporosis was defined by T-score $\leq 2.5$ at any of the two skeletal sites. As per the NBHA recommendations, subjects were defined to have osteoporosis also in case of lowtrauma hip fracture (independently of BMD) or osteopenia (T-score $\leq-1>-2.5$ ) at any of the two skeletal sites in association with at least one major low-trauma fracture (vertebral, proximal humerus, pelvis, or distal forearm) occurred after the menopause or if they have the 10-year probability for either major or hip fracture $\geq 20$ and $\geq 3 \%$, respectively, based on FRAX ${ }^{\circledR}$ [5]. Finally, subjects with DeFRA values $\geq 20 \%$ for major fractures and $\geq 3 \%$ for hip fractures were defined as having osteoporosis.

Written informed consent was obtained from all participants after full explanation of the study details. The protocol was approved by the Ethics Committees of any of the Center participating in the study.

\section{Statistical analysis}

Descriptive statistics are expressed as mean \pm SD. Since some of the data may show an asymmetric distribution, first, second and third quartiles have been also calculated. The Wilcox test for paired samples was used to compared data from FRAX ${ }^{\circledR}$ and DeFRA calculation. The prevalence of osteoporosis was assessed on the basis of the NBHA criteria [5] and the DeFRA criterion in the entire cohort and expressed as percentage. The prevalence of osteopenia was also calculated. The prevalence of the clinical risk factors included in the FRAX ${ }^{\circledR}$ and DeFRA was calculated in the entire cohort.

The association between values derived from FRAX ${ }^{\circledR}$ and DeFRA was assessed using Spearman's rank correlation coefficient. Inter-criteria agreement between the two algorithms was assessed using Cohen's kappa statistic.

$p$ values $<0.05$ were considered significant and the $\mathrm{R}$ package (version 3.02) was used for statistical calculations.

\section{Results}

Table 1 shows mean values \pm SD of demographic, BMD, FRAX $^{\circledR}$ and DeFRA data, as well as the prevalence of major osteoporotic fractures and osteoporosis in the entire cohort. We observed a significant difference between FRAX ${ }^{\circledR}$ and DeFRA data using Wilkcox test $(p<0.0001)$. We observed a $33 \%$ and $37.3 \%$ of the cohort having FRAX ${ }^{\circledR}$ and DeFRA values $\geq 3 \%$, respectively.

The prevalence of osteoporosis, as assessed by BMD criteria was $36.6 \%$ (Table 1). In particular, $28.4 \%$ of subjects had lumbar spine osteoporosis and $16.2 \%$ had osteoporosis at the femoral neck and $8.2 \%$ had both lumbar spine and femoral neck osteoporosis. The prevalence of osteopenia was $52 \%$.

According to the NBHA criteria, the prevalence of osteoporosis was assessed on the basis of the presence of low-trauma femur fracture and independently on BMD and was $2.5 \%$, and in case of osteopenia and at least one major low-trauma fracture and resulted in $9.3 \%$ of subjects (Table 1). The FRAX ${ }^{\circledR}$ and DeFRA criteria for the definition of osteoporotic patients was also applied and showed a 32.6 and $37.4 \%$ prevalence of osteoporosis in our cohort, respectively (Table 1). Taking into account any of the aforementioned criteria, the general prevalence of osteoporosis in our cohort was 57\% (Table 1). The prevalence of osteoporosis, as defined by any of the aforementioned criteria and according to age class is reported in Fig. 1. We observed a significant difference in the prevalence of osteoporosis between the north (50\%) and the center-south of the country (59\%; $p<0.0001)$. 
Table 1 Characteristics of the cohort of women: mean \pm SD [median $\left(25^{\circ}\right.$ percentile; $75^{\circ}$ percentile)]

\begin{tabular}{|c|c|}
\hline Characteristics & $n=3247$ \\
\hline Age (years) & $65.7 \pm 8.5[66(59 ; 72)]$ \\
\hline Weight $(\mathrm{kg})$ & $64.8 \pm 12[63(56 ; 72)]$ \\
\hline Height $(\mathrm{cm})$ & $157[156(152 ; 160)]$ \\
\hline BMI $\left(\mathrm{kg} / \mathrm{m}^{2}\right)$ & $26.5 \pm 4.8[25,8(23 ; 29)]$ \\
\hline L1-L4 BMD $\left(\mathrm{g} / \mathrm{cm}^{2}\right)$ & $0.856 \pm 0.140[0.839(0.762 ; 0.939)]$ \\
\hline T-score & $-1.7 \pm 1.3[-1.9(-2.6 ;-1.0)]$ \\
\hline FN BMD $\left(\mathrm{g} / \mathrm{cm}^{2}\right)$ & $0.669 \pm 0.105[0.660(0.599 ; 0.732)]$ \\
\hline T-score & $-1.6 \pm 0.9[-1.7(-2.25 ;-1.1)]$ \\
\hline TH BMD $\left(\mathrm{g} / \mathrm{cm}^{2}\right)$ & $0.794 \pm 0.119[0.789(0.718 ; 0.869)]$ \\
\hline T-score & $-1.2 \pm 1[-1.3(-1.8 ;-0.6)]$ \\
\hline Major fractures ( $\%$ of the entire population) & 23 \\
\hline Femur & 2.5 \\
\hline Vertebral & 5.5 \\
\hline Proximal humerus & 4 \\
\hline Pelvis & 1.5 \\
\hline Distal forearm & 9.7 \\
\hline \multicolumn{2}{|l|}{ FRAX $^{\circledR}$ without Neck BMD $(\%)$} \\
\hline Major fractures & $11.4 \pm 8.8[8.9(5.2 ; 14.7)]$ \\
\hline Hip fractures & $4.5 \pm 6.3[2.3(0.9 ; 5.5)]$ \\
\hline \multicolumn{2}{|l|}{ FRAX $^{\circledR}$ with Neck BMD $(\%)^{*}$} \\
\hline Major fractures & $10.2 \pm 7.3[8.2(5.1 ; 12.8)]$ \\
\hline Hip fractures & $3.3 \pm 4.9[1.7(0.7 ; 3.9)]$ \\
\hline \multicolumn{2}{|l|}{ DeFRA $(\%)$} \\
\hline Major fractures & $11 \pm 9.4[8.2(5.5 ; 12.9)]$ \\
\hline Hip fractures & $3.9 \pm 5.9[2(0.8 ; 4.6)]$ \\
\hline \multicolumn{2}{|c|}{ Prevalence of osteoporosis ( $\%$ of the entire population) } \\
\hline By NBHA criteria & $57^{\#}$ \\
\hline $\mathrm{BMD}$ & 36.6 \\
\hline Low-trauma femur fracture & 2.5 \\
\hline Osteopenia + one major low-trauma fracture & 9.3 \\
\hline FRAX $^{\circledR}$ & 32.6 \\
\hline By DeFRA & 37.4 \\
\hline
\end{tabular}

${ }^{*} p<0.0001$ compared to DeFRA using Wilkcox test; ${ }^{*}$ General prevalence calculated considering any of the NBHA criteria
Table 2 reports the prevalence of clinical risk factors included in FRAX ${ }^{\circledR}$ and DeFRA calculation. As shown, the presence of previous fracture, particularly non-spine/ non-hip fracture, parental history of hip fracture and the current smoking were the most common risk factors in our cohort.

We found a significant association between FRAX $^{\circledR}$ and DeFRA as far as risk for major fracture $(r=0.920$, $p<0.0001)$ and for hip fracture $(r=0.971, p<0.0001)$. There was a high concordance between the two algorithms in the evaluation of both major fracture and hip fracture risk resulting in a Cohen's kappa equal to 0.834 $(p<0.0001)$ which indicates an almost perfect concordance between the two criteria.

\section{Discussion}

Osteoporosis is a well-recognized major health problem worldwide and the burden of the disease is mostly associated with the occurrence of hip and vertebral fracture [28]. Studies on the prevalence of osteoporosis, fractures, and risk factors for fracture have been conducted in different countries, but none in Italy. In this context, our study reported for the first time the prevalence of osteoporosis in Italian postmenopausal women aged 50 and older and focused not only on the BMD measurement, but also on the assessment of other factors defining fracture risk and recently included in the definition of osteoporosis [5]. We observed a $36.6 \%$ prevalence of osteoporosis and $51 \%$ of osteopenia, accounting for 
Fig. 1 Prevalence of osteoporosis (\% of the entire cohort) defined by the presence of at least one of the NBHA criteria and distributed according to age class
Table 2 Prevalence of clinical risk factors included in FRAX ${ }^{\circledR}$ and DeFRA

\begin{tabular}{llc}
\hline Clinical risk factor & FRAX $^{\circledR}$ & DeFRA \\
\hline Previous fractures (\%) & 31.6 & 31.6 \\
Spine and hip (\%) & - & 8 \\
1 & - & 7.7 \\
$>1$ & - & 0.3 \\
Non-spine/non-hip (\%) & - & 27.2 \\
1 & - & 23.6 \\
$>1$ & - & 3.6 \\
Parental history of hip fractures (\%) & 14.6 & 14.6 \\
Current smoking (\%) & 11.7 & 11.7 \\
$<10$ cigarettes/day & - & 6.4 \\
$>10$ cigarettes/day & - & 5 \\
Glucocorticoids (\%) & 6 & 6 \\
$>2.5<5$ mg/day & - & 4.4 \\
$>5$ mg/day & - & 1.3 \\
Rheumatoid arthritis (\%) & 4.5 & 4.5 \\
Secondary osteoporosis (\%) & 10.2 & 10.2 \\
Alcohol (\%) & 1.8 & 1.8 \\
\hline
\end{tabular}

Data are expressed as percentage (\%) of subjects in the entire cohort

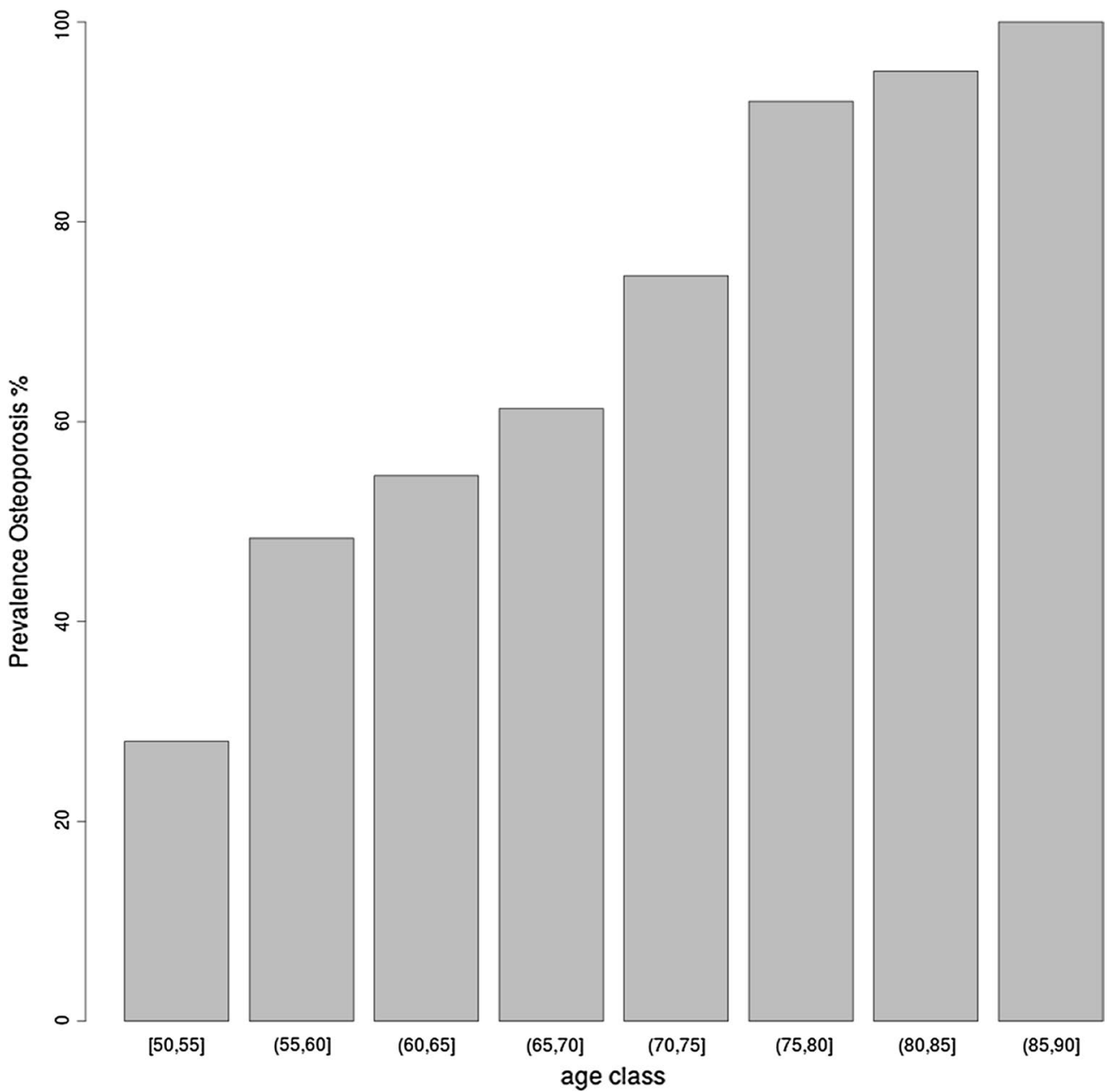

$87 \%$ of subjects with low bone mass, as assessed by DXA. This figure is particularly relevant, especially in relation with data from other countries [19, 29]. Data collected in over 50 million US women from 2005 to 2010 showed a prevalence of osteoporosis of $15.5 \%$, with $8.2 \%$ of the women having femoral neck osteoporosis after adjusting for age, sex, and ethnic distribution of the US population [19]. Notwithstanding the differences between the studies, mostly related to differences in the age and ethnicity composition between the two cohorts, our results further confirm the presence of international disparity in the rate of osteoporosis and osteoporotic fracture [30]. Data from our study are indeed in line with those from other Italian cohorts showing a high prevalence of low bone mass among postmenopausal women [22]. Several factors should be taken into account in the evaluation of these findings, mostly related to genetic, environmental and lifestyle determinants. Given to the complex pathogenesis of the disease [31], difference in the genetic susceptibility to osteoporosis and fracture across countries is indeed advocated as one of the main mechanisms, having bone mass and bone architecture, as well as other factors associated with fracture risk strong genetic basis [32-34]. Furthermore, 
other evidence suggests that difference in demographic features, as well as in some of the indicators of development in a given country, life expectancy and the socioeconomic status correlate with the different hip fracture rates across countries [33]. As far as data on fractures, the rate of $23 \%$ for major osteoporotic fractures is in line with previous reports from other Italian cohorts [22, 35]. Conversely, data from the NHANES population showed lower rate of hip, spine and distal forearm fractures in women (1.4-3.3\% depending on age range) compared to our study and previous studies in Italian cohorts [20, 22]. In addition, the high rate of hypovitaminosis D commonly observed in observational studies and the almost absent habit of using fortified foods in Italy (as it is the case in other countries) should be considered as other important risk factors accounting for international difference in the epidemiology of osteoporosis and fracture $[36,37]$. Beyond the aforementioned genetic and environmental factors, these data could also be interpreted on the basis of different levels of awareness on osteoporosis and fractures between the different populations, with a lower number of women in Italy performing screening tests and coming to attention of specialized centers before the fragility fracture occurs. Strategies aimed at reinforcing the primary prevention in the field of bone fragility, particularly among postmenopausal women, are, therefore, warranted on a National basis by designing prevention programs involving particularly primary healthcare providers. In this context, the use of algorithms for the assessment of fracture risk represents a valid instrument, as shown in our study. We observed indeed high mean values of both FRAX ${ }^{\circledR}$ and DeFRA as far as the probability of femur fracture that is comparable to what reported in a previous study from other Italian cohorts [38]. Notwithstanding the limited data demonstrating that patients with hip fracture risk $\geq 3 \%$ that represents the theoretical threshold for defining an elevated fracture risk [5], will positively respond to osteoporotic treatment in terms of femur fracture reduction, these data account for the need of higher attention for this complication, particularly from a therapeutic point of view [39].

Notwithstanding the presence of mean DXA values in the range of osteopenia at femoral neck, the evaluation of the algorithms gives a further contribution in the identification of women who need treatment and/or intervention on modifiable factors and/or a strict follow-up because at medium-high risk for fracture. As far as risk factors, our study confirmed what previously observed in other Italian cohorts showing how previous fragility fracture, parental history of fracture, smoking and secondary osteoporosis represent the two most frequent factors after history of fracture $[22,35]$.

The presence of strong association and concordance between FRAX ${ }^{\circledR}$ and DeFRA accounts for a high value of the derived algorithm in the assessment of fracture risk.
The higher value of DeFRA compared to FRAX ${ }^{\circledR}$ further confirms the possibility of using DeFRA in specific subgroups of patients [22]. Additionally, our results suggest the possibility of further developments of DeFRA by including other covariates that demonstrated to strongly influence fracture risk [40]. Recent data from a cohort study in Manitoba, Canada have indeed demonstrated as parental hip fracture occurring at the age $\geq 80$ has no significant association with the risk of major osteoporotic fracture, while the association was strong particularly when fracture in the parent occurred before the age of 70 [40]. The inclusion of age of the parental hip fracture in the DeFRA calculation would, therefore, be an interesting point for future research.

Limitations of our study pertain its observational nature and, therefore, the absence of any follow-up data in our cohort that would have given the possibility to assess the sensitivity and predictive value of the algorithms, particularly the DeFRA. In addition, we have data only on clinical vertebral fractures and can hypothesize that this complication of the disease has been underestimated by the current data. We also acknowledge that it is not possible to exclude a selection bias on the basis of a possible higher sensitivity to the issue of osteoporosis by those women who decided to participate for many reasons (experienced fracture, family history of fracture, etc.). Nonetheless, this is the first cohort study in Italy that evaluated the prevalence of osteoporosis by DXA and by the use of the NBHA criteria and reported the prevalence of the major clinical osteoporotic fractures and the main risk factors for fracture.

In conclusion, our study showed that more that the half of postmenopausal women aged 50 and older in Italy have osteoporosis on the basis of the most recent criteria. Additionally, there is a high rate of major osteoporotic fractures and relevant high risk of femur fracture, as assessed by the FRAX $^{\circledR}$ and DeFRA algorithm. We believe that our results should be considered particularly in relation to the need to increase prevention strategies on modifiable risk factors and therapeutic intervention.

Acknowledgements The authors thank the Società Italiana dell'Osteoporosi, del Metabolismo Minerale e delle Malattie dello Scheletro (SIOMMMS) for funding the project.

\section{Compliance with ethical standards}

Conflict of interest Francesco Bertoldo declares the following conflicts of interest: advisory board, consulting fees: Abiogen, Amgen, Bayer, Italfarmaco; lecture fees: Abiogen, Amgen, Lilly. Gerolamo Bianchi has received honoraria and/or consulting fees from Abbvie, Abiogen, Alfa-Sigma, Amgen, BMS, Celgene, Chiesi, Eli Lilly, GSK, Janssen, Medac, Merck Sharp \& Dohme, Novartis, Pfizer, Roche, Sanofi Genzyme, and Servier. Andrea Giustina: Abiogen, IPSEN, Pfizer. Salvatore Minisola served as speaker for Abiogen, Amgen, Bruno Farmaceutici, Diasorin, Eli Lilly, Fujii and in advisory board of Abiogen. He received consultancy from Bruno Farmaceutici. Cristiana Cipriani, Jessica Pepe, Francesco Paolo Cantatore, Addolorata Corrado, Marco 
Di Stefano, Bruno Frediani, Davide Gatti, Teresa Porcelli, Giancarlo Isaia, Maurizio Rossini, Luciano Nieddu, Giuseppe Girasole, Mario Pedrazzoni declare that they have no conflict of interest.

Ethical approval All procedures performed in studies involving human participants were in accordance with the ethical standards of the institutional and/or national research committee and with the 1964 Helsinki declaration and its later amendments or comparable ethical standards.

Informed consent Informed consent was obtained from all individual participants included in the study.

\section{References}

1. Johnston CC Jr, Slemenda CW, Melton LJ 3rd (1991) Clinical use of bone densitometry. N Engl J Med 324(16):1105-1109. doi:10.1056/NEJM199104183241606

2. WHO Study Group (1994) Assessment of fracture risk and its application to screening for postmenopausal osteoporosis. World Health Organization technical report series 843:1-129

3. Nih Consensus Development Panel on Osteoporosis Prevention D, Therapy (2001) Osteoporosis prevention, diagnosis, and therapy. JAMA 285(6):785-795

4. Siris ES, Boonen S, Mitchell PJ, Bilezikian J, Silverman S (2012) What's in a name? What constitutes the clinical diagnosis of osteoporosis? Osteoporos Int 23(8):2093-2097. doi:10.1007/ s00198-012-1991-0

5. Siris ES, Adler R, Bilezikian J, Bolognese M, Dawson-Hughes B, Favus MJ, Harris ST, Jan de Beur SM, Khosla S, Lane NE, Lindsay R, Nana AD, Orwoll ES, Saag K, Silverman S, Watts NB (2014) The clinical diagnosis of osteoporosis: a position statement from the National Bone Health Alliance Working Group. Osteoporos Int 25(5):1439-1443. doi:10.1007/s00198-014-2655-z

6. Lewiecki EM, Binkley N (2016) What we don't know about osteoporosis. J Endocrinol Invest 39(5):491-493. doi:10.1007/ s40618-016-0442-8

7. Kanis JA, Oden A, Johnell O, Johansson H, De Laet C, Brown J, Burckhardt P, Cooper C, Christiansen C, Cummings S, Eisman JA, Fujiwara S, Gluer C, Goltzman D, Hans D, Krieg MA, La Croix A, McCloskey E, Mellstrom D, Melton LJ 3rd, Pols H, Reeve J, Sanders K, Schott AM, Silman A, Torgerson D, van Staa T, Watts NB, Yoshimura N (2007) The use of clinical risk factors enhances the performance of BMD in the prediction of hip and osteoporotic fractures in men and women. Osteoporos Int 18(8):1033-1046. doi:10.1007/s00198-007-0343-y

8. Adami S, Bianchi G, Brandi ML, Di Munno O, Frediani B, Gatti D, Giannini S, Girasole G, Minisola G, Minisola S, Nuti R, Pedrazzoni M, Rossini M, Varenna M (2010) Validation and further development of the WHO 10-year fracture risk assessment tool in Italian postmenopausal women: project rationale and description. Clin Exp Rheumatol 28(4):561-570

9. Vescini F, Attanasio R, Balestrieri A, Bandeira F, Bonadonna S, Camozzi V, Cassibba S, Cesareo R, Chiodini I, Francucci CM, Gianotti L, Grimaldi F, Guglielmi R, Madeo B, Marcocci C, Palermo A, Scillitani A, Vignali E, Rochira V, Zini M (2016) Italian association of clinical endocrinologists (AME) position statement: drug therapy of osteoporosis. J Endocrinol Invest 39(7):807-834. doi:10.1007/s40618-016-0434-8

10. Nevitt MC, Ross PD, Palermo L, Musliner T, Genant HK, Thompson DE (1999) Association of prevalent vertebral fractures, bone density, and alendronate treatment with incident vertebral fractures: effect of number and spinal location of fractures. The Fracture Intervention Trial Research Group. Bone 25(5):613-619

11. Kanis JA, Johansson H, Johnell O, Oden A, De Laet C, Eisman JA, Pols H, Tenenhouse A (2005) Alcohol intake as a risk factor for fracture. Osteoporos Int 16(7):737-742. doi:10.1007/ s00198-004-1734-y

12. Vestergaard P, Mosekilde L (2003) Fracture risk associated with smoking: a meta-analysis. J Intern Med 254(6):572-583

13. Dennison E, Cooper C (2002) Epidemiology of glucocorticoidinduced osteoporosis. Front Hormone Res 30:121-126

14. Yuen SY, Rochwerg B, Ouimet J, Pope JE (2008) Patients with scleroderma may have increased risk of osteoporosis. A comparison to rheumatoid arthritis and noninflammatory musculoskeletal conditions. J Rheumatol 35(6):1073-1078

15. Borba VZ, Matos PG, da Silva Viana PR, Fernandes A, Sato EI, Lazaretti-Castro M (2005) High prevalence of vertebral deformity in premenopausal systemic lupus erythematosus patients. Lupus 14(7):529-533

16. Cooper C, Cole ZA, Holroyd CR, Earl SC, Harvey NC, Dennison EM, Melton LJ, Cummings SR, Kanis JA, Epidemiology ICWGoF (2011) Secular trends in the incidence of hip and other osteoporotic fractures. Osteoporos Int 22(5):1277-1288. doi:10.1007/ s00198-011-1601-6

17. Kanis JA, Oden A, McCloskey EV, Johansson H, Wahl DA, Cooper C, Epidemiology IOFWGo, Quality of L (2012) A systematic review of hip fracture incidence and probability of fracture worldwide. Osteoporos Int 23(9):2239-2256. doi:10.1007/ s00198-012-1964-3

18. Curtis EM, van der Velde R, Moon RJ, van den Bergh JP, Geusens P, de Vries F, van Staa TP, Cooper C, Harvey NC (2016) Epidemiology of fractures in the United Kingdom 1988-2012: variation with age, sex, geography, ethnicity and socioeconomic status. Bone 87:19-26. doi:10.1016/j.bone.2016.03.006

19. Wright NC, Looker AC, Saag KG, Curtis JR, Delzell ES, Randall S, Dawson-Hughes B (2014) The recent prevalence of osteoporosis and low bone mass in the United States based on bone mineral density at the femoral neck or lumbar spine. J Bone Miner Res 29(11):2520-2526. doi:10.1002/jbmr.2269

20. Wright NC, Saag KG, Dawson-Hughes B, Khosla S, Siris ES (2016) The impact of the new National Bone Health Alliance (NBHA) diagnostic criteria on the prevalence of osteoporosis in the USA. Osteoporos Int. doi:10.1007/s00198-016-3865-3

21. D’Amelio P, Spertino E, Martino F, Isaia GC (2013) Prevalence of postmenopausal osteoporosis in Italy and validation of decision rules for referring women for bone densitometry. Calcif Tissue Int 92(5):437-443. doi:10.1007/s00223-013-9699-5

22. Bonaccorsi G, Fila E, Cervellati C, Romani A, Giganti M, Rossini M, Greco P, Massari L (2015) Assessment of fracture risk in a population of postmenopausal Italian women: a comparison of two different tools. Calcif Tissue Int 97(1):50-57. doi:10.1007/ s00223-015-0009-2

23. Maggi S, Noale M, Giannini S, Adami S, Defeo D, Isaia G, Sinigaglia L, Filipponi P, Crepaldi G, Group ES (2006) Quantitative heel ultrasound in a population-based study in Italy and its relationship with fracture history: the ESOPO study. Osteoporos Int 17(2):237-244. doi:10.1007/s00198-005-1985-2

24. Genant HK, Grampp S, Gluer CC, Faulkner KG, Jergas M, Engelke K, Hagiwara S, Van Kuijk C (1994) Universal standardization for dual X-ray absorptiometry: patient and phantom cross-calibration results. J Bone Miner Res 9(10):1503-1514. doi:10.1002/jbmr.5650091002

25. Pedrazzoni M, Girasole G, Bertoldo F, Bianchi G, Cepollaro C, Del Puente A, Giannini S, Gonnelli S, Maggio D, Marcocci C, Minisola S, Palummeri E, Rossini M, Sartori L, Sinigaglia L (2003) Definition of a population-specific DXA reference standard in Italian women: the Densitometric Italian Normative 
Study (DINS). Osteoporos Int 14(12):978-982. doi:10.1007/ s00198-003-1521-1

26. Looker AC, Orwoll ES, Johnston CC Jr, Lindsay RL, Wahner HW, Dunn WL, Calvo MS, Harris TB, Heyse SP (1997) Prevalence of low femoral bone density in older U.S. adults from NHANES III. J Bone Miner Res 12(11):1761-1768. doi:10.1359/ jbmr.1997.12.11.1761

27. Kanis JA, McCloskey EV, Johansson H, Oden A, Melton LJ 3rd, Khaltaev N (2008) A reference standard for the description of osteoporosis. Bone 42(3):467-475. doi:10.1016/j. bone.2007.11.001

28. Curtis EM, Moon RJ, Harvey NC, Cooper C (2017) The impact of fragility fracture and approaches to osteoporosis risk assessment worldwide. Bone. doi:10.1016/j.bone.2017.01.024

29. Wright NC, Saag KG, Curtis JR, Smith WK, Kilgore ML, Morrisey MA, Yun H, Zhang J, Delzell ES (2012) Recent trends in hip fracture rates by race/ethnicity among older US adults. J Bone Miner Res 27(11):2325-2332. doi:10.1002/jbmr.1684

30. Ballane G, Cauley JA, Luckey MM, Fuleihan Gel H (2014) Secular trends in hip fractures worldwide: opposing trends east versus west. J Bone Miner Res 29(8):1745-1755. doi:10.1002/jbmr.2218

31. Pepe J, Cipriani C, Cantatore FP, Fabbri A, Pola E, Vinicola V, Raimo O, Biamonte F, Pascone R, Ferrara C, Minisola S (2017) The effect of parathyroid hormone (1-84) treatment on serum bone morphogenetic protein 4 and vascular endothelial growth factor in postmenopausal women with established osteoporosis. J Endocrinol Invest 40(6):663-667. doi:10.1007/ s40618-017-0636-8

32. Ralston SH, Uitterlinden AG (2010) Genetics of osteoporosis. Endocr Rev 31(5):629-662. doi:10.1210/er.2009-0044

33. Cauley JA, Chalhoub D, Kassem AM, Fuleihan Gel H (2014) Geographic and ethnic disparities in osteoporotic fractures. Nat Rev Endocrinol 10(6):338-351. doi:10.1038/nrendo.2014.51
34. Alonso N, Ralston SH (2014) Unveiling the mysteries of the genetics of osteoporosis. J Endocrinol Invest 37(10):925-934. doi:10.1007/s40618-014-0149-7

35. Cavalli L, Guazzini A, Cianferotti L, Parri S, Cavalli T, Metozzi A, Giusti F, Fossi C, Black DM, Brandi ML (2016) Prevalence of osteoporosis in the Italian population and main risk factors: results of BoneTour Campaign. BMC Musculoskeletal Disord 17(1):396. doi:10.1186/s12891-016-1248-8

36. Romagnoli E, Caravella P, Scarnecchia L, Martinez P, Minisola S (1999) Hypovitaminosis D in an Italian population of healthy subjects and hospitalized patients. Br J Nutr 81(2):133-137

37. Carnevale V, Modoni S, Pileri M, Di Giorgio A, Chiodini I, Minisola S, Vieth R, Scillitani A (2001) Longitudinal evaluation of vitamin D status in healthy subjects from southern Italy: seasonal and gender differences. Osteoporos Int 12(12):1026-1030. doi: $10.1007 / \mathrm{s} 001980170012$

38. Pedrazzoni M, Girasole G, Giusti A, Barone A, Pioli G, Passeri G, Palummeri E, Bianchi G (2011) Assessment of the 10-year risk of fracture in Italian postmenopausal women using $\operatorname{FRAX}(\mathrm{R})$ : a north Italian multicenter study. J Endocrinol Invest 34(11):e386e391. doi:10.3275/7862

39. Adler RA (2016) Osteoporosis treatment: complexities and challenges. J Endocrinol Invest 39(7):719-720. doi:10.1007/ s40618-016-0437-5

40. Yang S, Leslie WD, Yan L, Walld R, Roos LL, Morin SN, Majumdar SR, Lix LM (2016) Objectively verified parental hip fracture is an independent risk factor for fracture: a linkage analysis of 478,792 parents and 261,705 offspring. J Bone Miner Res 31(9):1753-1759. doi:10.1002/jbmr.2849 